\title{
THE IMPACT OF THE SIBERIAN HIGH AND ALEUTIAN LOW ON THE SEA-ICE COVER OF THE SEA OF OKHOTSK
}

by

\author{
Claire L. Parkinson
}

(Oceans and Ice Branch/Code 671, NASA Goddard Space Flight Center, Greenbelt, MD 20771, U.S.A.)

\section{ABSTRACT}

Comparison of monthly averaged sea-ice distributions in the Sea of Okhotsk with atmospheric pressure data during the four winters having passive-microwave sea-ice coverage from the Nimbus 5 satellite, 1973-76, revealed a strong apparent relationship between the extent of the sea-ice cover and the influence of the Siberian High atmospheric pressure system. Examination of data for the years 1978-86, having passive-microwave coverage from the Nimbus 7 satellite, reveals that the strong correspondence found for 1973-76 between Okhotsk sea-ice extents and the Siberian High was not maintained in the 1978-86 period. A weaker correspondence continued, however, between the sea ice and the combined Siberian High/Aleutian Low system. A Siberian High/Aleutian Low index was created, and the correlation coefficient between that index and sea-ice extents in the midwinter month of February is 0.97 for the 1973-76 period and 0.52 for the $1978-86$ period. Primary reasons for the lack of a consistently strong monthly averaged ice/atmosphere correspondence are: the various oceanographic influences on the sea-ice cover, the failure of monthly averages to reflect fully the important shorter-term interactions between the ice and the atmosphere, and the fact that ice conditions in one month are influenced by ice conditions in previous months.

\section{INTRODUCTION}

Satellite passive-microwave data from the Electrically Scanning Microwave Radiometer (ESMR) on board the Nimbus 5 satellite allowed a mapping of Arctic sea-ice distributions for most of the period from the Nimbus 5 launch in December 1972 through the next four years (Parkinson and others, 1987). One of the most striking northern hemisphere interannual differences apparent in the four-year ESMR data set was the interannual contrast in the wintertime sea-ice distributions in the Sea of Okhotsk. In particular, in 1973 the sea was over half-covered with ice in January and almost entirely ice-covered in February, whereas in each of the other three years ice coverage in January was confined to near-shore regions along the north and west coasts and even in February most of the eastern, southern, and central portions of the sea remained ice-free.

The interannual contrast in the wintertime ice coverage in the Sea of Okhotsk over the years 1973-76 appeared to be readily explained by a corresponding interannual contrast in the positioning of the Siberian High pressure system (Parkinson and Gratz, 1983). This led to the tentative hypothesis that the ice cover in the Sea of Okhotsk is largely controlled by the positioning of the Siberian High. In order to test that hypothesis, later sea-ice data from the Scanning Multichannel Microwave Radiometer (SMMR) on board the Nimbus 7 satellite have been examined in conjunction with coincident atmospheric pressure data. This paper presents the results of that comparison, showing that the strong relationship found between the ice cover and the location of the Siberian High over the years 1973-76 was not maintained over the period of Nimbus 7 SMMR coverage, from October 1978 through August 1987. Thus the data from the SMMR years fail to confirm the original hypothesis of the Okhotsk ice extent being largely controlled by the positioning of the Siberian High.

\section{DATA SOURCES}

The sea-ice data used in this study were derived from Nimbus 5 ESMR data for 1973-76 and Nimbus 7 SMMR data for 1978-87. The ESMR and SMMR are both passive radiometers recording radiation at microwave wavelengths, ESMR with a single channel at $1.55 \mathrm{~cm}$ and SMMR with 10 channels, consisting of both horizontal and vertical polarizations at wavelengths of $0.81,1.4,1.7,2.8$, and $4.6 \mathrm{~cm}$. The spatial resolution of the ESMR data is approximately $30 \mathrm{~km}$, and the spatial resolution of the SMMR data varies from approximately $30 \mathrm{~km}$ for the $0.81 \mathrm{~cm}$ channels to approximately $150 \mathrm{~km}$ for the $4.6 \mathrm{~cm}$ channels. Because of the wide contrast in microwave emissivities between open water and sea ice, the data from either instrument can be used to determine ice concentrations and extents. Details on the ice concentration algorithms can be found in Parkinson and others (1987) for the ESMR data and in Cavalieri and others (1984) and Gloersen and Cavalieri (1986) for the SMMR data. Estimates of the uncertainties in the ice concentrations (for the first-year ice found in the Sea of Okhotsk) derived from the ESMR and SMMR data are $\pm 15 \%$ and $\pm 5-9 \%$ respectively (Parkinson and others, 1987; Cavalieri and others, 1984). Uncertainties in ice extents (defined as the area of ocean with ice concentration of at least 15\%) are less, estimated at under $4 \%$ by Parkinson and Cavalieri (1989). Northern hemisphere monthly average ESMR data exist for all months of the years 1973-76 except March, April, May, and August of 1973, June, July, and August of 1975, and November and December of 1976. SMMR data exist for all months from October 1978 through August 1987. Digitized ESMR and SMMR data are available from the National Snow and Ice Data Center (NSIDC), World Data Center A for Glaciology, Boulder, Colorado.

The atmospheric data used in this study consist of mean monthly sea level pressures. The monthly values were averaged from twice-daily data obtained in digitized form from the U.S. National Center for Atmospheric Research (NCAR) in Boulder, Colorado. The NCAR data are gridded to a $63 \times 63$ polar stereographic grid that covers the entire northern hemisphere and extends into the southern hemisphere at the grid corners. The monthly averaging was followed by contour mapping of the data, with a contour interval of 4 mbar. The data cover the period from 1972 through 1986, the latter being the final year processed and gridded at the time of the data request.

SEA OF OKHOTSK, ITS ICE COVER, AND OVERLYING PRESSURE SYSTEMS

The Sea of Okhotsk is a protected body of water to the northeast of Japan with an area of $1528000 \mathrm{~km}^{2}$ and 


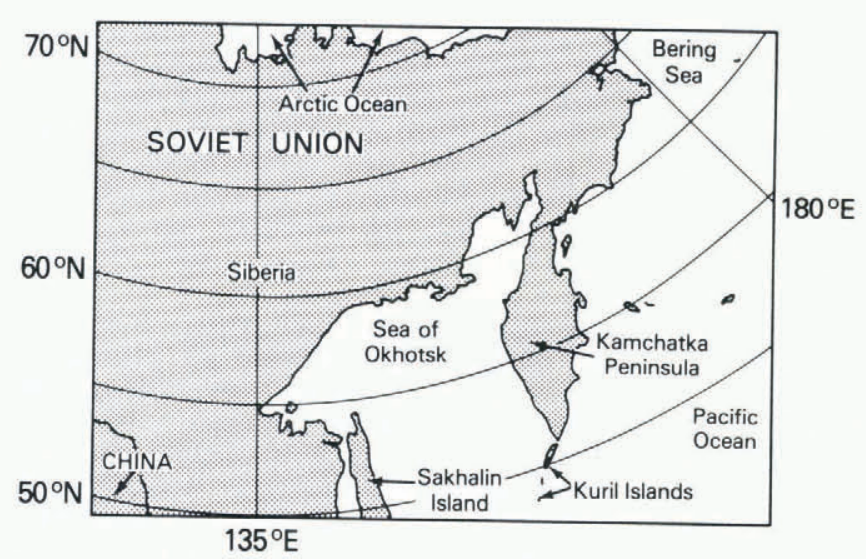

Fig. 1. Location map.

depths predominantly less than $1000 \mathrm{~m}$. It is bounded by the Kamchatka Peninsula, Siberia, Sakhalin Island, the Sea of Japan, and the Pacific Ocean (Fig. 1), with its only openings to the Sea of Japan being two narrow, shallow straits to the west and south of Sakhalin Island and its broader opening to the Pacific being constrained by the Kuril Island chain and an accompanying sill. Partly because of its protected nature, the Sea of Okhotsk tends to form ice earlier and retain it later than other oceanic regions of similar latitudes. Because of the grids used for the ESMR and SMMR data, the ice extents are actually calculated for a somewhat truncated Sea of Okhotsk, as depicted in Figure 1 , with the southernmost portion of the sea eliminated. The truncated sea covers $1206649 \mathrm{~km}^{2}$.

Typically, at least for the decades of the 1970s and 1980 s, the Sea of Okhotsk has ice-free or nearly ice-free conditions for most of the period from late June through early November. Sea ice begins to form in a few small and confined coastal locations in late November, predominantly in the northeastern and northwestern corners of the sea. It then expands in those two areas and forms along Sakhalin Island in December, along the remainder of the northern and western boundaries and part of Kamchatka Peninsula in January, and along much of the rest of the western Kamchatka coastline in February. The ice advances inward toward the center of the sea from all coastlines, with much of the sea covered to at least $30 \%$ ice concentration by mid-February, continuing through mid-March. After attaining its maximum extent of approximately $1 \times 10^{6} \mathrm{~km}^{2}$ in February or March, the ice cover begins to retreat first in the center of the basin and along the east coast, then along the north and west coasts. By June only coastal ice remains, this being largely in the northwest corner of the sea. These and other aspects of the seasonal cycle of sea ice in the Sea of Okhotsk are apparent in the 3-daily and daily ESMR and SMMR data sets, available from NSIDC. The reader is also referred to Watanabe (1967) for a summary

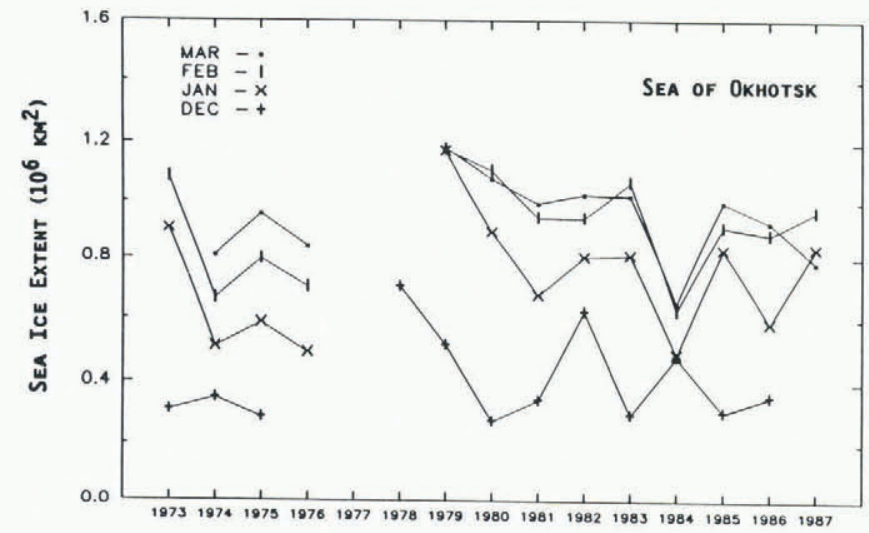

Fig. 2. Interannual variability of the December, January, February, and March monthly average ice extents in the Sea of Okhotsk. Extents were calculated from Nimbus 5 ESMR and Nimbus 7 SMMR data over the $1206649 \mathrm{~km}^{2}$ truncated Sea of Okhotsk region depicted in Figures 1, 3 and 5 . of Okhotsk ice conditions based on satellite data from the 1960 s and earlier in situ data. The strong east/west asymmetry both in the advance and retreat of the ice is due in large part to the warm, saline Pacific water moving northward along Kamchatka Peninsula in the West Kamchatka Current. This water delays ice formation along the west coast of Kamchatka during the ice-growth season and speeds ice decay in the same region during the ice-decay season.

The winter ice cover of the Sea of Okhotsk varies significantly from year to year, as illustrated for instance by the interannual variability in the monthly average sea-ice extents. Figure 2 depicts this interannual variability for the months December through March over the 1973-76 and 1978-87 period of ESMR/SMMR data coverage. The monthly average ice extent at its annual maximum in February or March ranges from $0.65 \times 10^{6} \mathrm{~km}^{2}$ in 1984 to $1.18 \times 10^{6} \mathrm{~km}^{2}$ in 1979 (Fig. 2). Other interannual differences in the Sea of Okhotsk ice cover are discussed in Akagawa (1973), Parkinson and Gratz (1983), and Alfultis and Martin (1987).

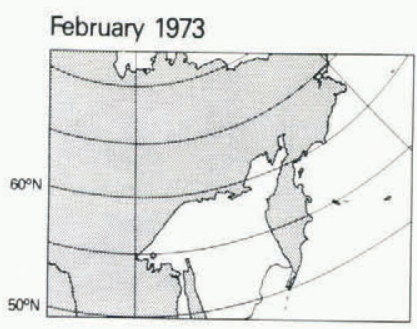

February 1974
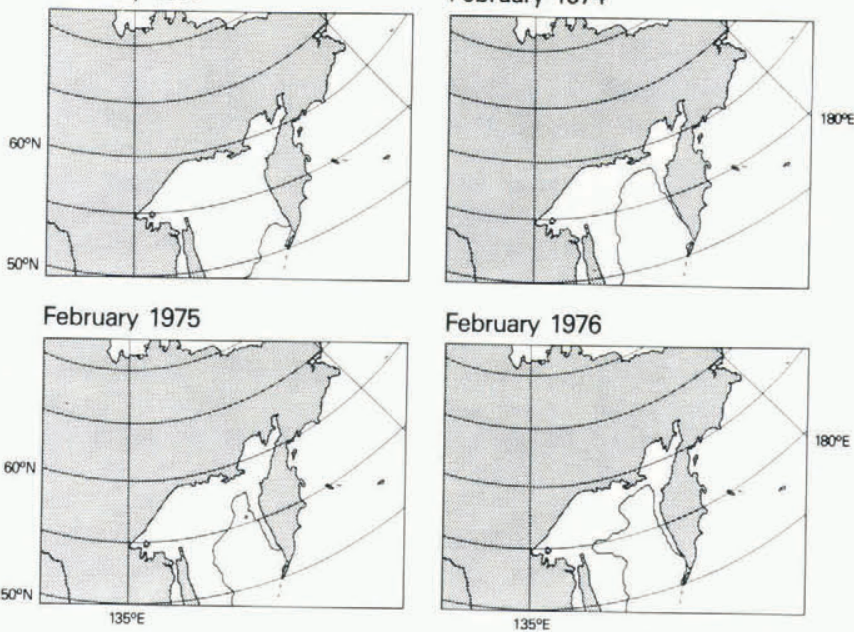

Fig. 3. February sea-ice distributions in the Sea of Okhotsk, 1973-76, determined from Nimbus 5 ESMR data. Heavy shading signifies land; light shading signifies sea ice of concentration equal to or greater than $15 \%$.

Atmospheric pressures and winds over the Sea of Okhotsk and surroundings typically undergo a pronounced seasonal variation, with a well-defined Siberian High to the west and Aleutian Low to the east in the winter months and a well-defined continental low to the southwest and Hawaiian High to the southeast in the summer months. Over the years of this study, the November-through-February monthly average pressure patterns over the Sea of Okhotsk consistently resulted from well-defined Siberian High and/or Aleutian Low systems. This remained the case in March for all years of the study except 1975 and 1985, when the atmospheric systems had dissipated to a considerable extent by March. More typically, the dissipation and initial transition toward the summer pressure regime occurred in April or May. These and other aspects of the atmospheric conditions are apparent from the hemispheric pressure data, available from NCAR.

\section{STRONG ICE/ATMOSPHERE CORRESPONDENCE 1973-} 76

The winter ice cover of the Sea of Okhotsk was significantly greater in 1973 than in any of the subsequent three years (Fig. 3). In fact, the heaviest ice cover recorded by the ESMR instrument for 1973-76 occurred in February 1973 (ESMR data are unavailable for March 1973), when the ice extent was $1.09 \times 10^{6} \mathrm{~km}^{2}$ (Fig. 2). This value exceeded the February ice extents in 1974, 1975, and 1976 by $64 \%, 37 \%$, and $55 \%$, respectively. The winter ice coverage was so much greater in 1973 than in 1974 and 1976 that even the January ice extent in 1973 exceeded the March maximum in the latter two years (Fig. 2). 

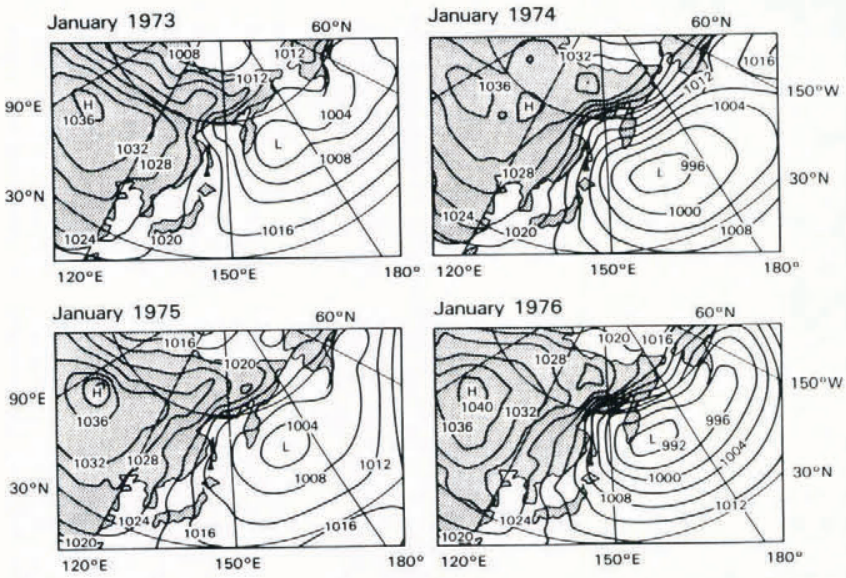

Fig. 4. Mean January sea level pressures over the Sea of Okhotsk and surrounding regions for 1973-76. The maps were plotted from digital data obtained from the Data Support Section, NCAR.

The contrast between the midwinter ice cover in the Sea of Okhotsk in 1973 and the ice covers in 1974-76 seems to be readily explained by the interannual contrast in the atmospheric pressure fields over the Sea of Okhotsk in January and February, particularly January. Specifically, in January 1974-76 the Aleutian Low dominated the flow over the sea, whereas in January 1973 the Siberian High and Aleutian Low had about equal prominence (Fig. 4). As a result, the January air flow over the Sea of Okhotsk in 1974-76 came largely from the Bering Sea, whereas much of the January air flow over the Sea of Okhotsk in 1973 came from the traditionally much colder region of northern Siberia. The cold north winds from Siberia in 1973 presumably contributed to advancing the ice cover both by advecting ice to the south and by leading to further cooling of the water. This provided a straightforward explanation for the much greater sea-ice extent in 1973, as noted by Parkinson and Gratz (1983).

\section{WEAK ICE/ATMOSPHERE CORRESPONDENCE 1978-86}

The strong ice/atmosphere correspondence found for the ESMR years between the ice extent and the influence of the Siberian High was not maintained during the SMMR years. In fact, the February ice extents in 1979 and 1980 exceeded the February 1973 ice extent (Fig. 2), and yet in neither 1979 nor 1980 was there a strong Siberian High component to the air flow over the Sea of Okhotsk (illustrated in Fig. 5 with the February pressure fields), as
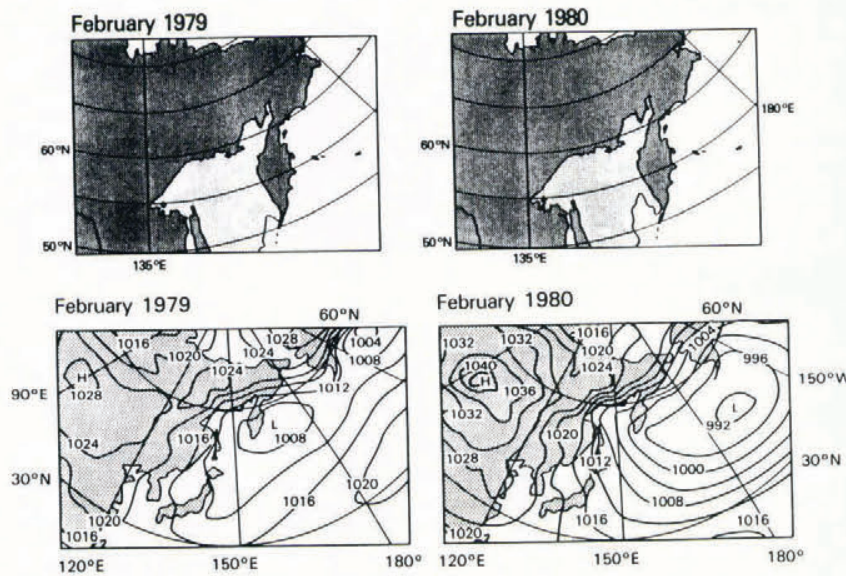

Fig. 5. February sea-ice distributions (top) and mean February sea level pressures (bottom) for the Sea of Okhotsk region for 1979 and 1980. The ice distributions were determined from Nimbus 7 SMMR data; the pressures were plotted from data obtained from the Data Support Section, NCAR. there had been in January 1973. Indeed, the SMMR years experienced a greater range in February ice extents than the ESMR years (Fig. 2), and yet during each of the eight SMMR winters $1978 / 79$ to $1985 / 86$, whether the ice cover was heavy or light the pressure system dominating the air flow over the Sea of Okhotsk was the Aleutian Low. This circumstance immediately refutes the hypothesis that a heavy ice cover is necessarily associated with a strong influence from the Siberian High.

However, even when the Siberian High is not a dominating influence over the Sea of Okhotsk, significant air flow into the sea can still derive from northeastern Siberia. Interannual and intra-annual differences in the positioning of the Aleutian Low result in air flowing into the Sea of Okhotsk from the Aleutian Low system sometimes after passing over $1000 \mathrm{~km}$ or more of northeastern Siberia, and other times after passing over only the narrow Kamchatka Peninsula subsequent to flow over the Bering Sea. In order to test the impact of this contrast on the Sea of Okhotsk ice cover, a Siberian High/Aleutian Low index was created for this study from the monthly average pressure fields. The index ranges from 1 for air flow deriving almost exclusively from the Bering Sea, passing over only the Kamchatka Peninsula before reaching the Sea of Okhotsk, to 5 for air flow containing a significant component from the Siberian High (Table I). Index values were determined visually, by examining each pressure plot, independently of sea-ice conditions. These index values were determined for November through March, the period of ice growth in the Sea of Okhotsk and also of a strong Siberian High/Aleutian Low winter pressure regime, and were then correlated with the Okhotsk ice extents in the midwinter month of February. The correlations were calculated both for the ESMR and SMMR years separately and for the combined data set (Table II).

Over the 12-year data period, the February pressure fields provide the highest correlation with the February ice extents $(0.63)$ and the January pressure fields provide the next highest correlation $(0.38)$ (Table II). Both the January and the February pressure fields had quite high correlations with the February ice extents over the short, four-year ESMR period ( 0.98 and 0.97 , respectively), confirming the qualitative interpretation discussed earlier. The very poor correlation between the January pressures and the February ice extents over the eight SMMR years $(-0.02)$ provides a strong counterweight to the high corresponding correlation for the ESMR years and badly damages possible speculations from the earlier data that the correlations reflect a strong lead/lag relationship, with the atmosphere leading the ice by a month. Although the February pressures and February ice extents remained positively correlated (at 0.52 ) over the SMMR period, the correlation had fallen well below the 0.97 for the ESMR period (Table II). It is clear that the high correlations for the ESMR years were not maintained for the SMMR years and cannot be assumed to be typical for the Sea of Okhotsk region.

\section{SUMMARY AND DISCUSSION}

It is widely recognized that the atmosphere and oceans have strong impacts on the world's sea-ice covers and conversely that the ice has strong impacts on the atmosphere and oceans (e.g., Barry, 1983; Parkinson and others, 1987). Partly because of the multiple influences, efforts to find consistently high correlations between the ice and other individual geophysical phenomena have generally not been successful. When a strong correspondence was found between the location of the Siberian High pressure system and the extent of sea ice in the Sea of Okhotsk over the years 1973-76, with the Siberian High having the greatest impact in the year with the most ice, it was hypothesized that perhaps the ice/atmosphere correspondence between the sea-ice cover and the atmospheric pressure fields over the Sea of Okhotsk might prove to be one of the few cases in which a high correlation would be confirmed. Here this hypothesis has been tested by examining the ice and pressure fields for additional years, specifically for the 1978-86 period of availability of sea-ice data from the Nimbus 7 SMMR and atmospheric pressure data from NCAR. It is found that the strong 


\begin{tabular}{lcccccccccccc} 
& $72 / 3$ & $73 / 4$ & $74 / 5$ & $75 / 6$ & $78 / 9$ & $79 / 80$ & $80 / 1$ & $81 / 2$ & $82 / 3$ & $83 / 4$ & $84 / 5$ & $85 / 6$ \\
\hline November & 4 & 2 & 4 & 5 & 5 & 4 & 2 & 3 & 3 & 4 & 4 & 3 \\
December & 3 & 2 & 2 & 5 & 4 & 4 & 1 & 3 & 4 & 3 & 4 & 4 \\
January & 5 & 1 & 2 & 2 & 4 & 1 & 4 & 3 & 1 & 2 & 4 & 3 \\
February & 3 & 1 & 2 & 1 & 2 & 2 & 2 & 1 & 4 & 1 & 1 & 2 \\
March & 2 & 2 & 5 & 1 & 3 & 3 & 4 & 3 & 3 & 2 & 5 & 2 \\
\hline
\end{tabular}

Key: 5. Strong influence from the Siberian High as well as the Aleutian Low; 4. Aleutian Low dominating, with air flow predominantly from northeastern Siberia; 3. Aleutian Low dominating, with comparable air flow from northeastern Siberia and the Bering Sea; 2. Aleutian Low dominating, with air flow mostly from the Bering Sea, partly from northeastern Siberia; 1. Aleutian Low dominating, with air flow almost exclusively from the Bering Sea.

TABLE II. CORRELATION COEFFICIENTS BETWEEN FEBRUARY ICE EXTENTS IN THE SEA OF OKHOTSK AND THE PRECEDING NOVEMBER-JANUARY, COINCIDENT FEBRUARY, AND SUBSEQUENT MARCH SIBERIAN HIGH/ALEUTIAN LOW INDEX VALUES. (Correlations are presented for the ESMR winters $1972 / 73-1975 / 76$, for the SMMR winters 1978/79-1985/86, and for the combined 12-winter data set.)

\begin{tabular}{lrrr} 
& $\begin{array}{l}\text { ESMR } \\
\text { years }\end{array}$ & $\begin{array}{c}\text { SMMR } \\
\text { years }\end{array}$ & $\begin{array}{c}\text { ESMR and SMMR } \\
\text { years }\end{array}$ \\
\hline & & & \\
November & 0.26 & 0.21 & 0.16 \\
December & -0.07 & 0.30 & 0.21 \\
January & 0.98 & -0.02 & 0.38 \\
February & 0.97 & 0.52 & 0.63 \\
March & 0.06 & 0.25 & 0.24 \\
& & & \\
\hline
\end{tabular}

correspondence during the ESMR years between the Siberian High and the Okhotsk ice was not maintained during the SMMR time period. In fact, for each of the winters $1978 / 79$ through $1985 / 86$, the Aleutian Low was the dominating atmospheric influence over the Sea of Okhotsk, and yet in several of those winters the sea was nearly fully ice covered. Interannual differences in the location and strength of the Aleutian Low had a noticeable apparent impact on the underlying ice cover, but the correlation between the pressure fields and the sea-ice extent was much reduced over what it had been during the ESMR years. Specifically, the correlation coefficient between a Siberian High/Aleutian Low pressure index and the sea-ice extent was 0.97 over the four ESMR Februarys but only 0.52 over the eight SMMR Februarys. More dramatically, the 0.98 correlation between the January pressure index and the February ice extents during the ESMR years was replaced by a -0.02 correlation for the SMMR years. A much longer data set would be needed to determine whether the high correlation or the low one is more typical.

The lack of a consistently high correlation between monthly averaged ice and atmospheric variables is presumably tied to several factors, among the primary ones being the failure of monthly averages to reflect fully the important shorter-term ice/atmosphere interactions and the existence of various oceanographic influences on the sea-ice cover. Examples of shorter-term ice/atmosphere interactions in the Sea of Okhotsk, and specifically the response of the sea-ice cover to transient weather systems, are given in Cavalieri and Parkinson (1987). Recent Okhotsk studies examining various oceanographic influences include the work of Parkinson and Gratz (1983) emphasizing the importance of convective depth, salinity, and ocean currents in determining the growth and decay patterns observed in the seasonal sea-ice cycle, and the work of Alfultis and Martin (1987) on the recurring Kashevarova polynya in the center of the Sea of Okhotsk and its apparent maintenance by the upwelling of warm water. An earlier study by Watanabe (1967) summarized ice drift in the Sea of Okhotsk and related it to various oceanographic factors. The Sea of Okhotsk ice cover is clearly influenced in important ways by both the atmosphere and the ocean, and high correlations between the ice cover and any one variable are unlikely to be maintained indefinitely.

\section{ACKNOWLEDGEMENTS}

This work was funded by the Oceanic Processes Branch at NASA Headquarters, whose support is greatly appreciated. Many thanks also go to R. Jenne and D. Joseph of NCAR's Data Support Section for providing the atmospheric sea level pressure data, and to R. Bindschadler, D. MacAyeal, and two anonymous reviewers for their comments on the manuscript.

\section{REFERENCES}

Akagawa, M. 1973. The characters of atmospheric circulation in the years with abnormal sea ice conditions along the Okhotsk coast of Hokkaido, Japan. Oceanogr. Mag., 24(2), 81-100.

Alfultis, M.A. and S. Martin. 1987. Satellite passive microwave studies of the Sea of Okhotsk ice cover and its relation to oceanic processes, 1978-1982. J. Geophys. Res., 92(C12), 13,013-13,028.

Barry, R.G. 1983. Arctic Ocean ice and climate: perspectives on a century of polar research. Ann. Assoc. Am. Geogr., 73(4), 485-501.

Cavalieri, D.J. and C.L. Parkinson. 1987. On the relationship between atmospheric circulation and the fluctuations in the sea ice extents of the Bering and Okhotsk seas. J. Geophys. Res., 92(C7), 7141-7162.

Cavalieri, D.J., P. Gloersen, and W.J. Campbell. 1984. Determination of sea ice parameters with the NIMBUS 7 SMMR. J. Geophys. Res., 89(D4), 5355-5369.

Gloersen, P. and D.J. Cavalieri. 1986. Reduction of weather effects in the calculation of sea ice concentration from microwave radiances. J. Geophys. Res., 91(C3), 3913-3919.

Parkinson, C.L. and D.J. Cavalieri. 1989. Arctic sea ice 1973-1987: seasonal, regional, and interannual variability. J. Geophys. Res., 94(C10), 14,499-14,523.

Parkinson, C.L. and A.J. Gratz. 1983. On the seasonal sea ice cover of the Sea of Okhotsk. J. Geophys. Res., 88(C5), 2793-2802.

Parkinson, C.L., J.C. Comiso, H.J. Zwally, D.J. Cavalieri, P. Gloersen, and W.J. Campbell. 1987. Arctic sea ice, 1973-1976: satellite passive-microwave observations. Washington, DC, National Aeronautics and Space Administration. (NASA SP-489.)

Watanabe, K. 1967. Summary of drift ice in the Okhotsk Sea. In Oura, H., ed. Physics of Snow and Ice. International Conference on Low Temperature Science ... 1966, Sapporo, Japan. Proceedings. Vol. I, Pt. 1. Hokkaido, Hokkaido University. Institute of Low Temperature Science, 667-686. 